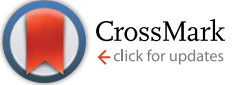

Cite this: RSC Adv., 2017, 7, 6229

\title{
Enhanced electrochemical oxidation of phenol by boron-doped diamond nanowire electrode
}

\author{
Choong-Hyun Lee, ${ }^{a}$ Eung-Seok Lee, ${ }^{a}$ Young-Kyun Lim, ${ }^{a}$ Kang-Hee Park, ${ }^{b}$ \\ Hee-Deung Park ${ }^{\mathrm{b}}$ and Dae-Soon Lim ${ }^{\star a}$
}

We fabricated a boron-doped diamond nanowire (BDDNW) electrode via metal-assisted chemical etching (MACE) of Si and electrostatic self-assembly of nanodiamond (ESAND) seeding to provide a large surface area during the electrochemical oxidation process. The effect of nanostructuring of the BDD surface on the electrochemical oxidation performance and the current efficiency of the electrode in phenol were examined. Uniformly covered BDD on nanotextured Si substantially enhanced the electrochemical activity of the electrode. The effective surface area calculated from cyclic voltammetry (CV) was enhanced several times compared to that of a conventional planar BDD electrode. The BDDNW electrode also exhibited greatly enhanced chemical oxygen demand (COD), total organic carbon (TOC) removal behavior, and current efficiency. Furthermore, because of its excellent oxidation performance, the BDDNW electrode also exhibited much lower energy consumption in the phenol oxidation process.

Received 4th November 2016 Accepted 3rd January 2017

DOI: 10.1039/c6ra26287b

www.rsc.org/advances candidates for the anode material, including $\mathrm{Pt}, \mathrm{IrO}_{2}, \mathrm{SnO}_{2}$, $\mathrm{PbO}_{2}$, glassy carbon (GC) and boron-doped diamond (BDD), have been investigated. ${ }^{15-18}$ Among these, BDD has been widely accepted as the most powerful anode material because of to its extremely high overpotential for the oxygen evolution reaction (OER). ${ }^{11,19,20}$ Additionally, BDD exhibits weak adsorption characteristics and tends to be chemically inert; consequently, numerous electrochemical wastewater treatment studies have been conducted on various organic oxidation mechanisms involving BDD anodes. ${ }^{21-23}$

Although BDD exhibits outstanding electro-oxidation performance, its utilization has thus far been limited to laboratory-scale experiments; its high cost makes it impractical in real wastewater treatment applications. To increase BDD electrode productivity and to overcome the drawback of its high cost, extensive effort has been directed toward achieving improved performance through modification of the conventional BDD electrode. The effect of the boron doping concentration of BDD on the oxidation of an aromatic compound has been studied by Bogdanowicz et al. ${ }^{24} \mathrm{~A}$ higher boron doping level of BDD was observed to lead to changes in diamond crystallites and in the density of the active sites on the surface, resulting in better oxidation performance. The influence of surface termination of BDD electrodes on organic oxidation has been investigated in several studies. ${ }^{25,26}$ The O-terminated BDD surface obtained via anodic polarization exhibits increased hydrophilicity, resulting in enhanced oxidation power of the anode. Souza et al. investigated the mineralization efficiency of 2,4-dichlorophenoxyacetic acid with respect to the $\mathrm{sp}^{3} / \mathrm{sp}^{2}$ ratio in BDD electrodes. ${ }^{27}$ They demonstrated that a higher content of $\mathrm{sp}^{3}$ diamond leads to more rapid oxidation.
${ }^{a}$ Department of Materials Science and Engineering, Korea University, Seoul 02841, Republic of Korea. E-mail: dslim@korea.ac.kr; Fax: +82-2-928-3584; Tel: +82-23290-3272

${ }^{b}$ School of Civil, Environmental and Architectural Engineering, Korea University, Seoul 02841, Republic of Korea. E-mail: heedeung@korea.ac.kr; Fax: +82-2-928-7656; Tel: $+82-2-3290-4861$ 
Because the quantity of the produced ${ }^{\circ} \mathrm{OH}$ and its mobility mainly depend on the anode material, the surface area of the electrode is a critical factor in determining its oxidation performance. Although many reviews and research articles emphasize the effects of a large surface area of electrodes, only a few studies have focused on the BDD electrode surface area. ${ }^{28-30} \mathrm{He}$ et al. fabricated a porous BDD electrode using a porous Ti substrate and demonstrated its electrochemical oxidation treatment performance. BDD pores with dimensions on the order of several tens of micrometers provided a large effective surface area and promoted current efficiency in the decomposition of various organic compounds. Nevertheless, fabrication of BDD on a Ti substrate requires long cooling time at the end of the CVD process because of the large thermal expansion gap and because of the problem of poorer long-term stability compared to that of Si-based BDDs, which results in delamination of the diamond film from the substrate due to residual stress. ${ }^{7,31}$ Moreover, the porous BDD of $\mathrm{He}$ et al. is limited to microsized structures, leaving the corresponding nanostructures, which are expected to exhibit substantially greater surface areas, unexplored.

To date, Si-based BDD nanostructures have been fabricated using various methods, including reactive-ion etching (RIE) of diamond, metal-assisted chemical etching (MACE) of Si, fabrication of carbon nanotube (CNT)-diamond hybrid structures and carbon dioxide activation. ${ }^{32-37}$ However, even though many techniques related to the nanostructuring of the BDD surface have been reported, these structures have only been applied in electrochemical sensor applications, not in electrochemical wastewater treatment processes.

In previous work, we examined the effect of micro-scaled texturing of BDD surface on dye (methyl orange) oxidation..$^{38}$ In this work, we demonstrate the electrochemical phenol oxidation performance of nanostructured BDD electrodes fabricated by a simple etching treatment of Si substrates. We achieved a substantially greater surface area of BDD using the MACE process and electrostatic self-assembly of nanodiamond (ESAND) seeding. Nanocrystalline BDDs were deposited onto a substrate with a nanotextured Si surface morphology. BDD nanowires (BDDNWs) were thereby formed, providing a much larger surface area than the microstructure electrode examined in our previous work. ${ }^{38}$ We compared the electrochemical oxidation performance of the BDD nanowire and of the conventional planar BDD by examining the cyclic voltammetry (CV), chemical oxygen demand (COD), total organic carbon (TOC) and energy consumption of these two electrode materials in the oxidation of phenol.

\section{Experimental procedure}

A p-type $\mathrm{Si}$ (100) wafer with $0.005 \Omega \mathrm{cm}$ resistivity was used as the substrate. The Si substrate was cleaned ultrasonically with ethanol and deionized water and subsequently immersed in $1 \%$ HF solution for $30 \mathrm{~min}$. For Si surface nanotexturing, the MACE process was conducted in a solution of $4.5 \mathrm{M} \mathrm{HF}$ and $0.01 \mathrm{M}$ $\mathrm{AgNO}_{3}{ }^{39}$ Prior to chemical etching, the Si substrate was immersed in Piranha solution for $1 \mathrm{~h}$ to provide a hydrophilic surface. The surface-treated $\mathrm{Si}$ substrate was dipped into an etching solution for $5 \mathrm{~min}$ at $50{ }^{\circ} \mathrm{C}$ and then into a $30 \% \mathrm{HNO}_{3}$ solution to remove residual silver dendrites.

To provide a diamond nucleation site, we seeded nanodiamonds onto the $\mathrm{Si}$ substrate using the ESAND seeding technique. The conventional planar Si and nanotextured $\mathrm{Si}$ substrate were coated with poly(diallyldimethylammonium chloride) (PDDA) to provide a positively charged surface. The negatively charged nanodiamond particles in a poly(sodium 4styrene sulfonate) (PSS) and nanodiamonds conjugate solution were electrostatically attached to the Si surfaces. Further information on the ESAND seeding method is provided in our previous report. ${ }^{40}$ After nanodiamond seeding, the planar BDD and BDDNW electrodes were synthesized by using hot-filament chemical vapor deposition (HFCVD) at a substrate temperature of $800{ }^{\circ} \mathrm{C}$ for $4 \mathrm{~h}$. As the carbon source, $1 \mathrm{vol} \%$ of $\mathrm{CH}_{4}$ in $\mathrm{H}_{2}$ was fed at a total flow rate of $100 \mathrm{sccm}$; the diluted $\mathrm{B}_{2} \mathrm{H}_{6}$ gas concentration was maintained at $[\mathrm{B}] /[\mathrm{C}]$ ratio of $5000 \mathrm{ppm}$ in both electrodes. The total chamber pressure was maintained at less than $10 \mathrm{kPa}$. The BDDNW fabrication processes, including the nanodiamond seeding process, are depicted in Fig. 1.

After deposition, the microstructures and electrochemical properties of the BDD nanowire electrode were analyzed. Fieldemission scanning electron microscopy (FESEM, Hitachi S4300) was used to examine the surface morphology. For Raman spectra analysis, Raman spectroscopy with a $514.5 \mathrm{~nm}$ Ar-ion laser was used A potentiostat (Princeton Applied Research, VersaSTAT3) with a three-electrode cell of platinum, $\mathrm{Ag} / \mathrm{AgCl}$ and a BDD nanowire electrode, representing the counter, reference and working electrodes, respectively, was used for electrochemical analyses.

'OH produced by electrodes was determined by DNPH $(2,4-$ dinitrophenylhydrazine) probe. ${ }^{41}$ Constant current density of 30 $\mathrm{mA} \mathrm{cm}{ }^{2}$ was applied in $0.5 \mathrm{M} \mathrm{Na}_{2} \mathrm{SO}_{4}$ solution with $5 \mathrm{mM}$ methanol for $10 \mathrm{~min}$. Formaldehyde was produced by reacting with methanol and transformed to a formaldehyde derivative by $20 \mathrm{mM}$ DNPH $(200 \mu \mathrm{L})$ with $1 \mathrm{M} \mathrm{HCl}(50 \mu \mathrm{L})$. Formaldehyde derivative was measured by Agilent 1260 high-performance liquid chromatography (HPLC) with UV absorbance at $360 \mathrm{~nm}$.

To evaluate the bulk oxidation performance of the electrode, we constructed a single-compartment electrolytic circulation cell that operates in galvanostatic mode. The BDD nanowire electrode and a stainless steel plate were used as the anode and the cathode, respectively; the area of both electrodes was $4 \times 4$

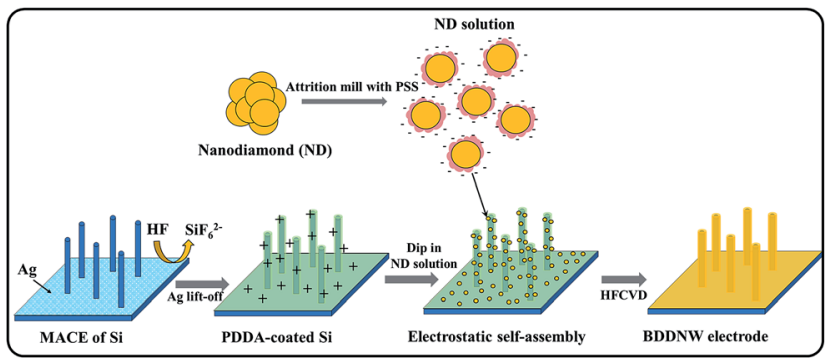

Fig. 1 Schematic of the fabrication process for a BDDNW electrode. 
$\mathrm{cm}^{2}$. The target organic compound was $1.0 \mathrm{mM}$ phenol in $0.5 \mathrm{M}$ $\mathrm{Na}_{2} \mathrm{SO}_{4}$ electrolyte $(500 \mathrm{~mL})$. The current density was fixed at 30 $\mathrm{mA} \mathrm{cm}{ }^{-2}$, and the total flow rate was $1 \mathrm{~L} \mathrm{~min}^{-1}$. During the 5 hours electrolysis, $2 \mathrm{~mL}$ of samples were extracted. After electrolysis, the COD (Hach DR-5000), the TOC (Shimadzu TOC-V $\mathrm{CPH}$ ) and the phenol concentration (HPLC) were determined.

\section{Results and discussion}

We fabricated conventional planar BDD and BDDNW electrodes via the ESAND seeding and HFCVD techniques. Fig. 2(a)-(d) shows the surface and cross-sectional microstructures of the electrodes. Diamond crystals with a size of a few hundred nanometers were formed on planar $\mathrm{Si}$, without forming pinholes. The thickness of the diamond layer in the planar BDD was approximately $200 \mathrm{~nm}$. In the case of the BDDNW electrode, nanocrystalline BDDs grew well along the etched Si surfaces; the average length and thickness of the BDD nanowires were $200 \mathrm{~nm}$ and $750 \mathrm{~nm}$, respectively. The ESAND method has been previously demonstrated to enable dense nanodiamond seeding on a complex nanotextured Si substrate without physical damage. ${ }^{36,38}$ Even though the planar BDD and BDDNW samples were fabricated under the same growth conditions, BDDNW exhibited a relatively lower growth rate, as indicated by its smaller crystal size and smaller film thickness. In Raman spectroscopy, both of planar BDD and BDDNW showed intense and clear nanocrystalline diamond peaks around $1130 \mathrm{~cm}^{-1}{ }^{42}$ BDDNW showed slightly lower $1332 \mathrm{~cm}^{-1}$ band which

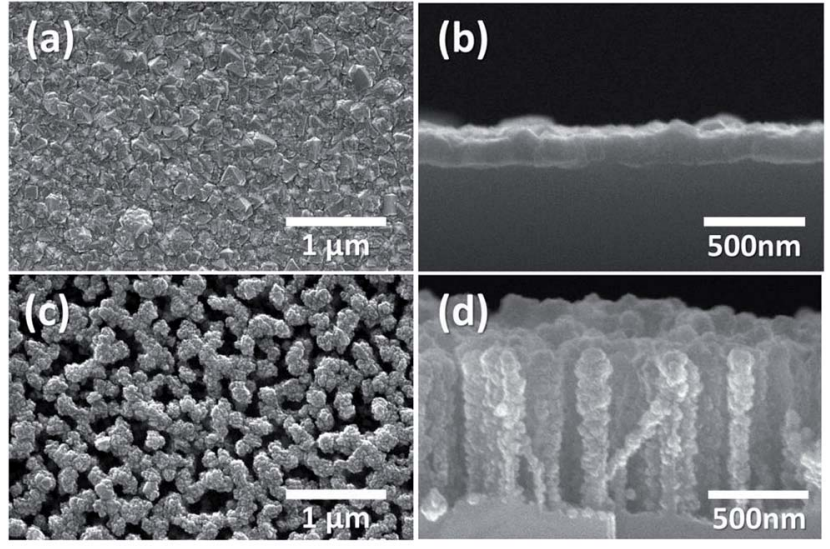

(e)

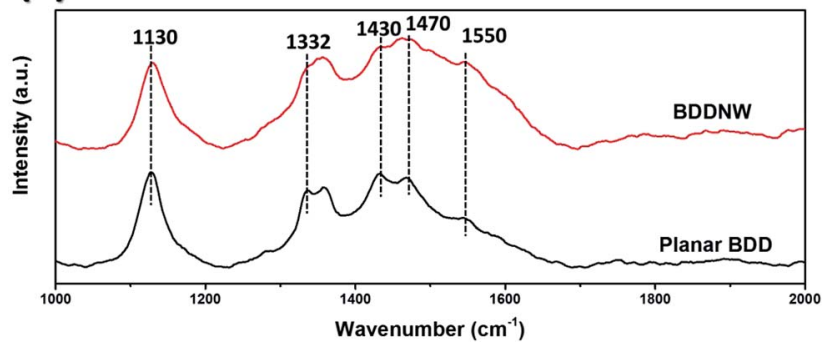

Fig. 2 (a) SEM image of top view of planar BDD, (b) side view of planar BDD, (c) top view of BDDNW, (d) side view of BDDNW and (e) Raman spectras of electrodes. attributed to the $\mathrm{sp}^{3}$ crystalline diamond phase and larger $\mathrm{G}$ peak $\left(1550 \mathrm{~cm}^{-1}\right)$ which attributed to the $\mathrm{sp}^{2}$ amorphous carbon..$^{43,44}$ The peaks at 1430 and $1470 \mathrm{~cm}^{-1}$ are related with transpolyacetylene at grain boundaries which are typically observed in synthetic diamond film. ${ }^{45}$ Even though crystalline $\mathrm{sp}^{3}$ diamond phase portion was decreased, a larger crystal population and additional grain boundaries via surface nanostructuring of BDD would enhance its electrochemical properties, as measured on the basis of its electro-oxidation performance.

Fig. 3 shows the electrochemical properties of the planar BDD and BDDNW electrodes. Cyclic voltammograms obtained at a scan rate of $50 \mathrm{mV} \mathrm{s}^{-1}$ in $0.5 \mathrm{M} \mathrm{H}_{2} \mathrm{SO}_{4}$ are shown in Fig. 3(a). Both planar and BDDNW electrodes exhibit the wide working potentials $(\sim 2.3 \mathrm{~V})$ and high OER potentials typically observed for BDD electrodes. The OER potential is important in the electro-oxidation process because the ${ }^{\circ} \mathrm{OH}$ evolution reaction and the OER are competitive reactions. A higher OER potential restrains the oxygen evolution from water electrolysis and produces more ${ }^{\circ} \mathrm{OH}$ on the surface of the anode. Therefore, BDD exhibits a substantially higher electro-oxidation power than other electrodes. ${ }^{46,47}$ The current density of the BDDNW electrode is greater than that of the planar BDD electrode because of
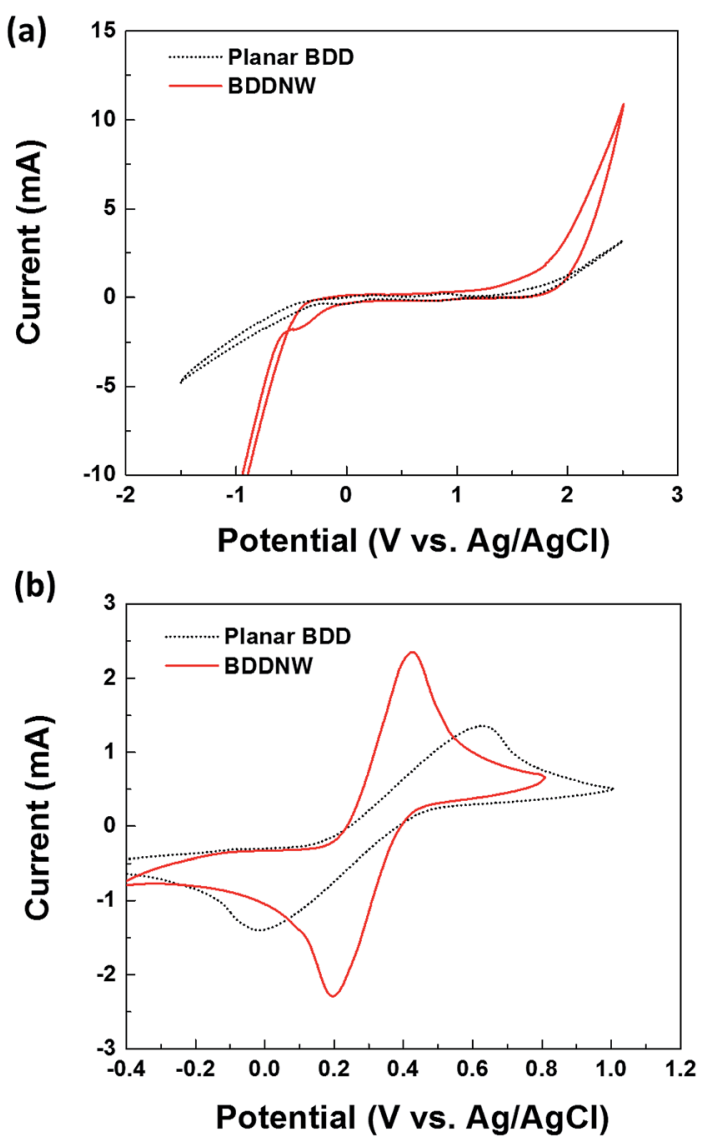

Fig. 3 Cyclic voltammograms of planar BDD and BDDNW electrodes in a (a) $0.5 \mathrm{M} \mathrm{H}_{2} \mathrm{SO}_{4}$ and (b) $3 \mathrm{M} \mathrm{KCl}$ solution containing $10 \mathrm{mM}$ $\mathrm{Fe}(\mathrm{CN})_{6}^{3-14-}$; the voltammograms were collected using a scan rate of $50 \mathrm{mV} \mathrm{s}^{-1}$ 
the BDDNWs' greater surface area; consequently, the BDDNW electrode should exhibit excellent electrochemical activity toward organic compounds. Increased surface area is also observed in the cyclic voltammograms for the $\mathrm{Fe}(\mathrm{CN})_{6}{ }^{3-/ 4-}$ redox couple, as shown in Fig. 3(b). In the case of the planar BDD, the anodic peak current $\left(I_{\mathrm{p}, \mathrm{a}}\right)$ and the cathodic peak current $\left(I_{\mathrm{p}, \mathrm{c}}\right)$ were $1.28 \mathrm{~mA}$ and $-1.27 \mathrm{~mA}$, respectively. The peak-to-peak separation potential $\left(\Delta E_{\mathrm{p}}\right)$ was $0.62 \mathrm{~V}$. However, the BDDNW electrode shows significantly enhanced $I_{\mathrm{p}, \mathrm{a}}(2.63$ $\mathrm{mA})$ and $I_{\mathrm{p}, \mathrm{c}}(-2.38 \mathrm{~mA})$ values and a significantly reduced $\Delta E_{\mathrm{p}}$ value $(0.22 \mathrm{~V})$. The lower $\Delta E_{\mathrm{p}}$ suggests that the electron transfer kinetics and the electrochemical activity of BDDNW are much better than those of the planar BDD electrode. ${ }^{48}$ Additionally, higher peak currents $\left(I_{\mathrm{p}}\right)$ indicate a larger effective surface area because the increase of $I_{\mathrm{p}}$ is proportional to the effective surface area. Fig. 4(a) shows variation of $I_{\mathrm{p}}$ with respect to the square root of the scan rate $\left(v^{1 / 2}\right)$ for the electrodes. Both peak currents show linear relationships, implying quasi-reversible behavior. Under this condition, the effective surface area is proportional to $I_{\mathrm{p}} / v^{1 / 2}$, as shown in the following equation:

$$
I_{\mathrm{p}}=\left(2.69 \times 10^{5}\right) n^{3 / 2} A D_{0}{ }^{1 / 2} C_{0}^{*} v^{1 / 2}
$$

where $n$ is the number of electrons in the redox reaction, $A$ is the electrode's surface area $\left(\mathrm{cm}^{2}\right), D$ is the diffusion coefficient for
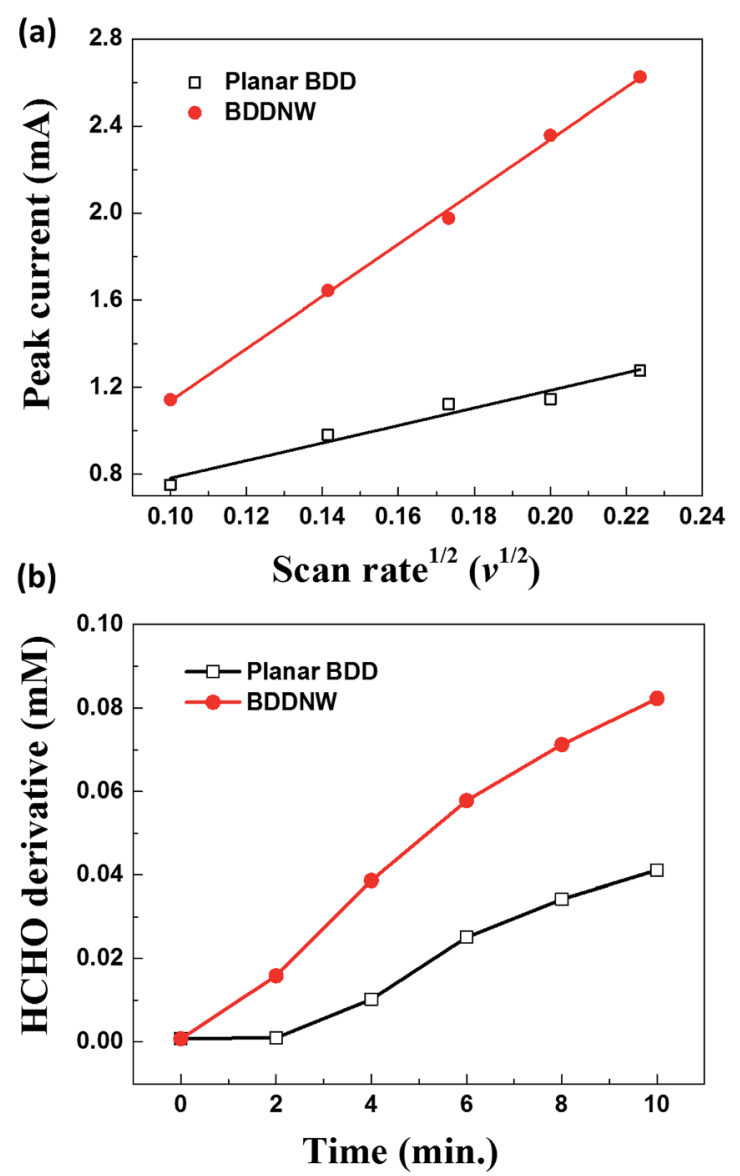

Fig. 4 (a) Peak current versus the square root of the scan rate and (b) formaldehyde produced by reacting ${ }^{\circ} \mathrm{OH}$ with methanol. the molecules in the solution $\left(\mathrm{cm}^{2} \mathrm{~s}^{-1}\right), C^{*}$ is the concentration of molecules in the bulk solution $\left(\mathrm{mol} \mathrm{cm}{ }^{-3}\right), v$ is the scan rate $\left(\mathrm{V} \mathrm{s}^{-1}\right)$ and $I_{\mathrm{p}}$ is the peak current (A). ${ }^{49}$ The calculated effective surface areas of the planar BDD and BDDNW electrodes were 1.61 and $4.78 \mathrm{~cm}^{2}$, respectively. Generally, a nanostructured surface exhibits a geometric area enhanced by a factor of thousands compared to that of its 2-dimensional planar surface counterpart; however, the BDDNW electrode exhibits an increase in the electrochemical effective area that is several orders of magnitude lower. Because surface regions that are not fully activated are also present, a large gap between the geometric area and the effective surface area is possible. ${ }^{50}$ Even though nanostructuring of BDD leads to only a threefold greater effective surface area, this greater surface area provides a substantially greater number of electrochemical reaction sites and generates ${ }^{\circ} \mathrm{OH}$ in substantially greater quantities, resulting in greater electro-oxidation efficiency. These results are reflected in the formaldehyde derivative concentration (Fig. 4(b)), which has positive relation with the amount of generation ${ }^{\circ} \mathrm{OH} \cdot{ }^{41}{ }^{\circ} \mathrm{OH}$ generation rate of BDDNW is always higher than planar BDD for the entire electrolysis time.

To evaluate the electro-oxidation performance, we conducted bulk electrolysis of $1 \mathrm{mM}$ phenol using a single-compartment electrolytic cell with parallel electrodes. Fig. 5 shows a decrease of the COD and the instantaneous current efficiency (ICE) as a function of specific charge amount on the planar BDD
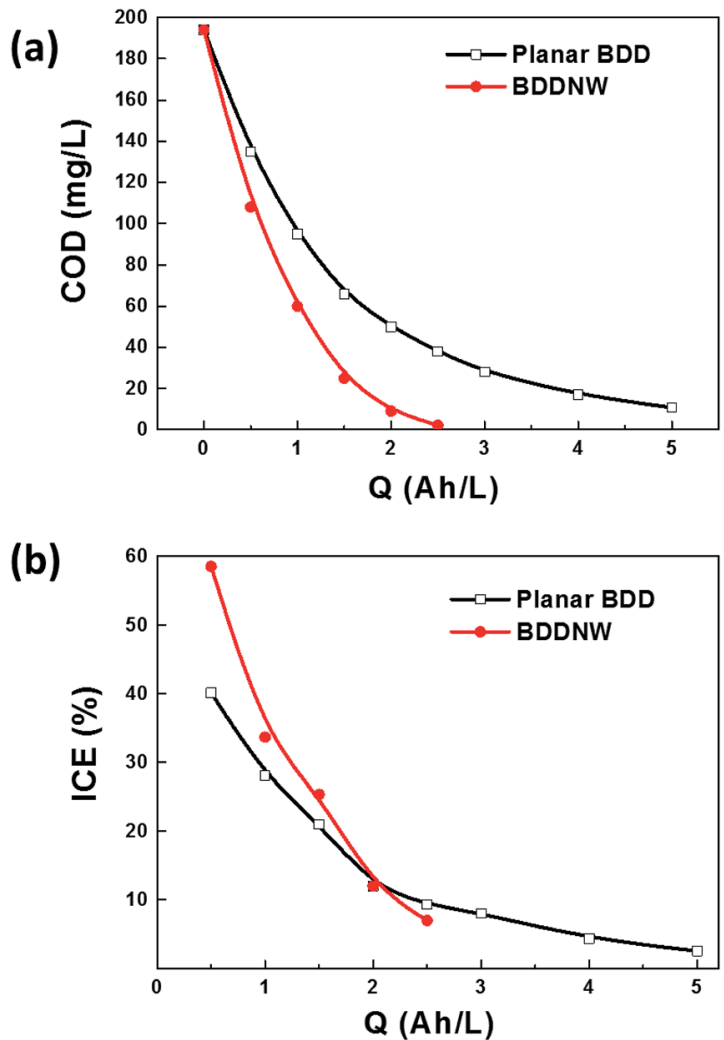

Fig. 5 (a) COD and (b) ICE curves for phenol oxidation on different electrodes. 
and BDDNW electrodes. The ICE for the anodic oxidation of phenol was calculated using the following equation:

$$
\operatorname{ICE}(\%)=F V \frac{\left[(\mathrm{COD})_{t}-(\mathrm{COD})_{t+\Delta t}\right]}{8 I \Delta t} \times 100
$$

where $F$ is the Faraday constant $\left(\mathrm{C} \mathrm{mol}^{-1}\right) ; V$ is the total volume of bulk electrolyte; (COD) $t$ and (COD) ${ }_{t+\Delta t}$ are the COD at times $t$ and $t+\Delta t\left(\mathrm{~g} \mathrm{~L}^{-1}\right)$, respectively; $I$ is the current $(\mathrm{A})$, and 8 is the equivalent mass of oxygen. ${ }^{51}$ Final COD removal in the planar BDD and BDDNW was $94.4 \%$ and $98.9 \%$, respectively. The COD value in the BDDNW at $2.5 \mathrm{~A} \mathrm{~h} \mathrm{~L}^{-1}$ was not recorded because of the detection limit $\left(>2 \mathrm{mg} \mathrm{L}^{-1}\right)$. COD removal occurred much more rapidly in $\mathrm{BDDNW}$; thus, the COD removal rate in the BDDNW electrode was substantially increased by the nanostructuring of the BDD surface. In the general case, the ICE was maintained at $100 \%$ at a high concentration of the organic compound and then exponentially decreased with decreasing concentration because of the depletion of organic compounds near the electrode surface, i.e., mass transfer limitation. ${ }^{52} \mathrm{He}$ et al. reported that the increased fraction of current efficiency of a microporous Ti/BDD electrode was smaller than they expected because the electrode's surface could not be exploited completely in a mass transport control situation. ${ }^{53}$ In our case, the initial ICE values were $\sim 40 \%$ and $\sim 60 \%$ for planar BDD and BDDNW, respectively, indicating that a quite low concentration of the organic compound was used in the system. However, the ICE values until a specific charge of $1.5 \mathrm{~A} \mathrm{~h} \mathrm{~L}^{-1}$ in BDDNW electrode were significantly higher than in the case of the planar BDD. In particular, COD removal was completed in only $2.5 \mathrm{~A} \mathrm{~h}$ $\mathrm{L}^{-1}$, which is earlier than in the case of phenol oxidation on the microstructured Ti/BDD electrode; thus, BDDNW could remove COD more efficiently even though it operated under masstransfer-limiting conditions. ${ }^{53}$

Fig. 6 shows the TOC, phenol removal and the mineralization efficiency (MCE). The MCE was calculated according to the equation:

$$
\operatorname{MCE}(\%)=\frac{\Delta(\text { TOC })_{\exp }}{\Delta(\text { TOC })_{\text {theor }}} \times 100
$$

where $\Delta(\text { TOC })_{\exp }$ is the experimental TOC variation and $\Delta(\text { TOC })_{\text {theor }}$ is the TOC variation theoretically calculated under the assumption that the applied electrical charge is only used for the mineralization reaction. ${ }^{21}$ The removal of TOC is typically slower than that of COD because electro-oxidation does not correspond to a direct combustion reaction. As was observed in the case of COD removal, the removal of TOC and phenol were faster in BDDNW. The total removal rates of TOC were $80 \%$ and $96.9 \%$ for the planar BDD and BDDNW, respectively. The total removal rates of phenol were $79 \%$ and $97 \%$ for the planar $\mathrm{BDD}$ and $\mathrm{BDDNW}$, respectively, meaning that BDDNW produced much more ${ }^{\circ} \mathrm{OH}$ than the planar BDD, which led to a higher derived rate for the complete combustion of phenol into $\mathrm{CO}_{2}$. These results are reflected in the MCE results (Fig. 6(b)), which show higher values for the entire electrolysis time, implying that the BDDNW electrode generated larger amounts of ${ }^{\circ} \mathrm{OH}$ during the electrochemical oxidation process. Because electrochemical phenol oxidation performance is (a)

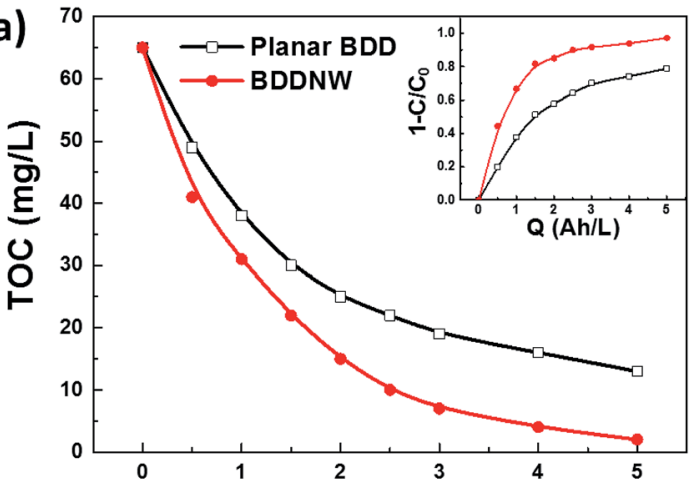

(b)

Q (Ah/L)

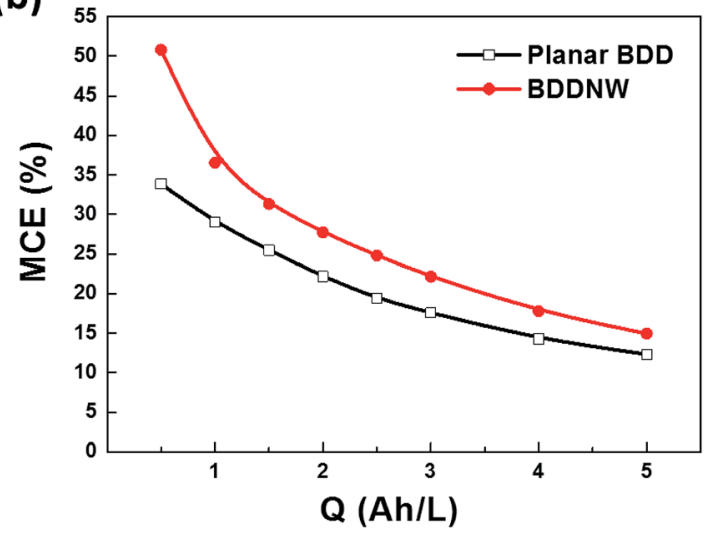

Fig. 6 (a) TOC, phenol removal (inset) and (b) MCE curves for phenol oxidation on different electrodes.

affected by various electrolysis conditions such as initial concentration, electrolyte, $\mathrm{pH}$, temperature and current density, the efficiency of BDDNW electrode may be further increased with optimizing process variables in future works. ${ }^{54,55}$

Fig. 7 shows specific energy consumption plotted with respect to phenol mineralization. The difference in the required specific energy increases dramatically with increasing the desired phenol mineralization. According to an extrapolation of the data, $27.5 \mathrm{~kW} \mathrm{~h} \mathrm{~m}^{-3}$ is required for $80 \%$ mineralization of

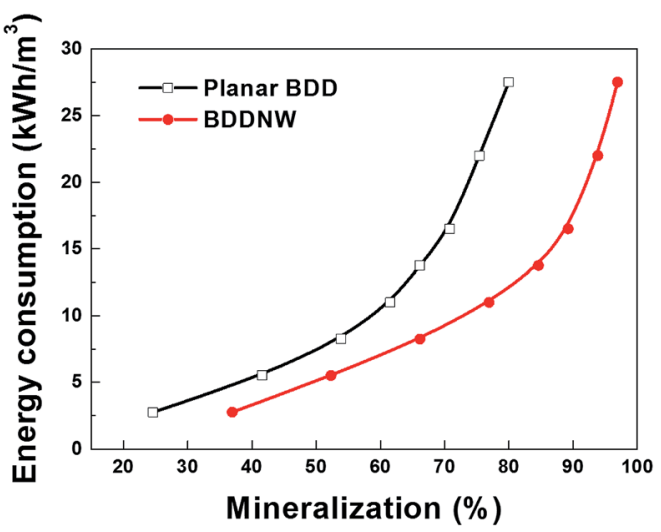

Fig. 7 Specific energy consumption with respect to phenol mineralization on different electrodes. 
phenol using the planar BDD electrode, whereas only $12.1 \mathrm{~kW} \mathrm{~h}$ $\mathrm{m}^{-3}$ is required using the BDDNW electrode. These results suggest that electrochemical oxidation of phenol using the BDDNW electrode is much more efficient from the standpoint of the economics of the oxidation process.

\section{Conclusions}

By using a metal-catalyzed silicon etching process and electrostatic nanodiamond seeding method, we successfully fabricated a BDDNW electrode for electrochemical oxidation processes. The BDDNW electrode exhibited an effective surface area that was three times greater than that of the planar-type BDD electrode; it also exhibited much faster electro-oxidation kinetics. In bulk electrolysis of phenol-containing water, the BDDNW electrode showed much higher COD and TOC removal rates as well as a higher current efficiency. Because of the large effective surface area of the nanowires, the BDDNW electrode generated large amounts of ${ }^{\circ} \mathrm{OH}$. Despite the mass transfer limitation, the BDDNW electrode exhibited highly improved electrochemical oxidation performance compared to the microtextured BDD electrode investigated in our previous study as well as compared to other microstructured BDD electrodes. Additionally, nanostructuring of the BDD electrode reduced specific energy consumption for $80 \%$ mineralization of phenol by a factor of more than 2 compared to the conventional planar BDD electrode. These results indicate that because of the larger surface area of nanostructured BDD, nanostructuring of the BDD electrode may solve the problem associated with the high production cost per unit area of BDD electrodes and can potentially be applied in applications involving real wastewater.

\section{Acknowledgements}

This work was supported by Korea Ministry of Environment (MOE) as "Public Technology Program based on Environmental Policy” (No. E416-00070-0604-0).

\section{References}

1 M. Cheng, G. M. Zeng, D. L. Huang, C. Lai, P. Xu, C. Zhang and Y. Liu, Chem. Eng. J., 2016, 284, 582-598.

2 J. Hoigne, Water Sci. Technol., 1997, 35, 1-8.

3 M. Pera-Titus, V. Garcia-Molina, M. A. Banos, J. Gimenez and S. Esplugas, Appl. Catal., B, 2004, 47, 219-256.

4 S. W. da Silva, C. R. Klauck, M. A. Siqueira and A. M. Bernardes, J. Hazard. Mater., 2015, 282, 241-248.

5 A. R. F. Pipi, I. Sires, A. R. De Andrade and E. Brillas, Chemosphere, 2014, 109, 49-55.

6 K. Ikehata, N. J. Naghashkar and M. G. Ei-Din, Ozone: Sci. Eng., 2006, 28, 353-414.

7 Y. Tian, X. M. Chen, C. Shang and G. H. Chen, J. Electrochem. Soc., 2006, 153, J80-J85.

8 E. Brillas, I. Sires and M. A. Oturan, Chem. Rev., 2009, 109, 6570-6631.

9 Y. G. Adewuyi, Environ. Sci. Technol., 2005, 39, 8557-8570.
10 S. G. Kumar and K. S. R. K. Rao, RSC Adv., 2015, 5, 33063351.

11 A. Kraft, M. Stadelmann and M. Blaschke, J. Hazard. Mater., 2003, 103, 247-261.

12 A. Sakalis, K. Fytianos, U. Nickel and A. Voulgaropoulos, Chem. Eng. J., 2006, 119, 127-133.

13 T. Bechtold, A. Turcanu and W. Schrott, Diamond Relat. Mater., 2006, 15, 1513-1519.

14 R. E. Palma-Goyes, F. L. Guzman-Duque, G. Penuela, I. Gonzalez, J. L. Nava and R. A. Torres-Palma, Chemosphere, 2010, 81, 26-32.

15 J. T. Xing, D. H. Chen, W. Zhao, X. L. Peng, Z. L. Bai, W. W. Zhang and X. X. Zhao, RSC Adv., 2015, 5, 53504-53513.

16 S. P. Li, Y. H. Li, X. Y. Zeng, W. R. Wang, R. X. Shi and L. N. Ma, RSC Adv., 2015, 5, 68700-68713.

17 Y. Wang, C. C. Shen, L. F. Li, H. Y. Li and M. M. Zhang, RSC Adv., 2016, 6, 30598-30610.

18 A. Urtiaga, P. Fernandez-Castro, P. Gomez and I. Ortiz, Chem. Eng. J., 2014, 239, 341-350.

19 J. H. T. Luong, K. B. Male and J. D. Glennon, Analyst, 2009, 134, 1965-1979.

20 W. Zhang, S. Y. Zhu, R. Luque, S. Han, L. Z. Hu and G. B. Xu, Chem. Soc. Rev., 2016, 45, 715-752.

21 E. Brillas, B. Boye, I. Sires, J. A. Garrido, R. M. Rodriguez, C. Arias, P. L. Cabot and C. Comninellis, Electrochim. Acta, 2004, 49, 4487-4496.

22 F. Montilla, P. A. Michaud, E. Morallon, J. L. Vazquez and C. Comninellis, Electrochim. Acta, 2002, 47, 3509-3513.

23 P. Canizares, C. Saez, J. Lobato and M. A. Rodrigo, Ind. Eng. Chem. Res., 2004, 43, 6629-6637.

24 R. Bogdanowicz, A. Fabianska, L. Golunski, M. Sobaszek, M. Gnyba, J. Ryl, K. Darowicki, T. Ossowski, S. D. Janssens, K. Haenen and E. M. Siedlecka, Diamond Relat. Mater., 2013, 39, 82-88.

25 C. Chen, E. Nurhayati, Y. Juang and C. Huang, J. Environ. Sci., 2016, 45, 100-107.

26 D. A. Tryk, H. Tachibana, H. Inoue and A. Fujishima, Diamond Relat. Mater., 2007, 16, 881-887.

27 F. L. Souz, C. Saez, M. R. V. Lanza, P. Canizares and M. A. Rodrigo, Electrochim. Acta, 2016, 187, 119-124.

28 B. P. Chaplin, Environ. Sci.: Processes Impacts, 2014, 16, 11821203.

29 A. Kraft, Int. J. Electrochem. Sci., 2007, 2, 355-385.

30 M. Panizza, P. A. Michaud, G. Cerisola and C. Comninellis, Electrochem. Commun., 2001, 3, 336-339.

31 P. Y. Lim, F. Y. Lin, H. C. Shih, V. G. Ralchenko, V. P. Varnin, Y. V. Pleskov, S. F. Hsu, S. S. Chou and P. L. Hsu, Thin Solid Films, 2008, 516, 6125-6132.

32 Y. S. Zou, Y. Yang, Y. L. Zhou, Z. X. Li, H. Yang, B. He, I. Bello and W. J. Zhang, J. Nanosci. Nanotechnol., 2011, 11, 79147919.

33 N. J. Yang, H. Uetsuka and C. E. Nebel, Adv. Funct. Mater., 2009, 19, 887-893.

34 D. B. Luo, L. Z. Wu and J. F. Zhi, ACS Nano, 2009, 3, 21212128. 
35 H. Zanin, P. W. May, D. J. Fermin, D. Plana, S. M. C. Vieira, W. I. Milne and E. J. Corat, ACS Appl. Mater. Interfaces, 2014, 6, 990-995.

36 S. K. Lee, M. J. Song, J. H. Kim, T. S. Kan, Y. K. Lim, J. P. Ahn and D. S. Lim, NPG Asia Mater., 2014, 6, e115.

37 J. F. Zhang, T. Nakai, M. Uno, Y. Nishiki and W. Sugimoto, Carbon, 2014, 70, 207-214.

38 J. Y. Bak, C. H. Lee, J. D. Kim and D. S. Lim, J. Korean Phys. Soc., 2016, 68, 109-114.

39 K. Q. Peng, Z. P. Huang and J. Zhu, Adv. Mater., 2004, 16, 7376.

40 J. H. Kim, S. K. Lee, O. M. Kwon and D. S. Lim, J. Nanosci. Nanotechnol., 2009, 9, 4121-4127.

41 C. Tai, J. F. Peng, J. F. Liu, G. B. Jiang and H. Zou, Anal. Chim. Acta, 2004, 527, 73-80.

42 K. Siuzdak, R. Bogdanowicz, M. Sawczak and M. Sobaszek, Nanoscale, 2015, 7, 551-558.

43 J. V. Macpherson, Phys. Chem. Chem. Phys., 2015, 17, 29352949.

44 P. W. May, W. J. Ludlow, M. Hannaway, P. J. Heard, J. A. Smith and K. N. Rosser, Chem. Phys. Lett., 2007, 446, 103-108.
45 S. Prawer and R. J. Nemanich, Philos. Trans. R. Soc., A, 2004, 362, 2537-2565.

46 M. Panizza and G. Cerisola, Electrochim. Acta, 2003, 48, 34913497.

47 M. Panizza and G. Cerisola, Electrochim. Acta, 2004, 49, 32213226.

48 X. H. Kang, J. Wang, H. Wu, I. A. Aksay, J. Liu and Y. H. Lin, Biosens. Bioelectron., 2009, 25, 901-905.

49 A. J. Bard and L. R. Faulkner, Electrochemical Methods: Fundamentals and Applications, Wiley, New York, 2000.

50 S. Trasatti and O. A. Petrii, J. Electroanal. Chem., 1992, 327, 353-376.

51 C. Comninellis and C. Pulgarin, J. Appl. Electrochem., 1991, 21, 703-708.

52 C. A. Martinez-Huitle and S. Ferro, Chem. Soc. Rev., 2006, 35, 1324-1340.

53 Y. P. He, W. M. Huang, R. L. Chen, W. L. Zhang and H. B. Lin, Sep. Purif. Technol., 2015, 149, 124-131.

54 P. Canizares, J. Lobato, R. Paz, M. A. Rodrigo and C. Saez, Water Res., 2005, 39, 2687-2703.

55 C. Comninellis and A. Nerini, J. Appl. Electrochem., 1995, 25, 23-28. 